\title{
High dose steroid treatment in cerebral infarction
}

\author{
JOHN W NORRIS, VLADIMIR C HACHINSKI
}

\begin{abstract}
Steroid treatment is widely used in acute cerebral infarction yet its value is controversial. High dose dexamethasone $\mathbf{4 8 0} \mathrm{mg}$ over 12 days) was given in a double blind, randomised controlled trial to 113 consecutive eligible patients with acute cerebral infarction admitted to an acute stroke unit. Those with stroke for more than 48 hours, known embolic sources, diabetes, and infection were excluded. Death and quality of survival were recorded over 21 days.
\end{abstract}

The active drug group (54 patients) matched the placebo group (59 patients) for age, initial stroke score, delay in beginning treatment, and other relevant variables. The two groups did not differ significantly in death rate or quality of survivorship. The small difference in mortality between the two groups may have represented a marginal therapeutic effect, which might reach significance in a larger sample. The widespread use of steroids in response to such a marginal therapeutic gain would expose large numbers of patients with stroke to more serious hazards of steroid treatment and convert patients who would otherwise have died into neurovegetative survivors.

High dose steroid treatment was ineffective in ischaemic stroke, and the data suggest that further evaluation by a larger multicentre trial is not justified.

\section{Introduction}

Few controversies in the management of acute stroke are more contentious than that concerning the use of steroids. The enthusiasm generated by early anecdotal reports ${ }^{12}$ waned when data from controlled trials yielded conflicting results. ${ }^{3.5}$ Steroid treatment in the form of dexamethasone is still widely administered in acute stroke. In a recent survey of 70 physicians in Toronto (35 internists and 35 neurologists) $39(56 \%)$ prescribed steroids for stroke "sometimes," 30 (43\%) "never," and one "always." Steroid treatment was usually reserved for patients with impaired consciousness due to presumed cerebral oedema.

Megadose treatment (up to 10 times the usual dose) overcomes criticism that the steroid dosage used previously was too small and too brief. ${ }^{6}$ Initial favourable reports of high dosage dexamethasone in head injury prompted the following study in patients with acute cerebral infarction. ${ }^{7}$

\section{Patients and methods}

Consecutive patients admitted to the Toronto acute stroke unit were entered into the study once informed consent from the patient or nearest relative had been obtained. Excluded were patients with $(a)$ stroke that had occurred more than 48 hours previously, $(b)$ cerebral haemorrhage seen on

MacLachlan Stroke Unit, Department of Neurosciences, Sunnybrook Medical Centre and University of Toronto, Toronto, Canada

JOHN W NORRIS, MD, FRCP, neurologist

Investigative Stroke Unit, University Hospital and Department of Clinical Neurological Sciences, University of Western Ontario, London, Canada VLADIMIR C HACHINSKI, MD, FRCP(C), neurologist

Correspondence to: Dr J W Norris, Sunnybrook Medical Centre, 2075 Bayview Avenue, Toronto, Canada M4N 3M5. computed tomography, $(c)$ diabetes mellitus (in our previous study uncontrollable blood sugar concentrations produced iatrogenic hypoglycaemic damage $\left.^{5}\right),(d)$ infection (in our previous study a patient with unsuspected septicaemia developed a brain abscess), (e) mild stroke (stroke score less than 45 points),${ }^{9}(f)$ massive terminal stroke, $(g)$ dementia or previous stroke (making the new neurological deficit difficult to assess), or $(h)$ an established cardiac embolic source (for example, mural thrombosis, where clinical deterioration could not be distinguished from fresh emboli).

\section{TREATMENT STRATEGY}

Starting within 48 hours of the onset of symptoms dexamethasone or matching placebo was given intravenously for 24 hours to all patients. Patients were assigned in a controlled, double blind fashion to receive the drug or placebo using a table of random numbers. Drug or placebo was then given by mouth unless the patient was unable to swallow. The total dose was $480 \mathrm{mg}$, starting with $24 \mathrm{mg}$ four times a day and progressively diminishing the doses until the 12th day. Alkalis and antidyspeptic drugs were not given, since the evidence that steroids produce peptic ulceration is controversial. ${ }^{10}$

Patients developing diabetes mellitus, sepsis, or gastrointestinal haemorrhage were immediately withdrawn from the study.

Neurological disability was assessed on admission, on alternate days until day 12 , and finally on day 21 using the Toronto stroke scoring system, which was previously correlated with clinical function. ${ }^{9}$ In brief, this system scores only neurological deficits present in the acute stage of stroke and therefore omits activities of daily living and spasticity which become relevant in the subacute and chronic stages. Each variable is given a score and weighted so that severe hemianopia may be equated with severe hemiplegia (table I).

TABLE I-Toronto stroke scoring system

\begin{tabular}{|c|c|c|c|c|}
\hline & & \multicolumn{3}{|c|}{ Score } \\
\hline $\begin{array}{l}\text { (1) Consciousness (alert, drowsy, stuporous, } \\
\text { light coma, deep coma) }\end{array}$ & & $0-4$ & $\times 25$ & $0-100$ \\
\hline (2) Paresis & $\left\{\begin{array}{c}\text { Face } \\
\text { Arm } \\
\text { Leg }\end{array}\right.$ & $\begin{array}{l}0-3 \\
0-4 \\
0-4\end{array}$ & $\begin{array}{l}\times 1 \\
\times \quad 3.5 \\
\times \quad 2.5\end{array}$ & $\begin{array}{lr}0- & 3 \\
0- & 14 \\
0- & 10\end{array}$ \\
\hline (3) Sensory impairment & $\left\{\begin{array}{c}\text { Face } \\
\text { Arm } \\
\text { Leg }\end{array}\right.$ & $\begin{array}{l}0-2 \\
0-2 \\
0-2\end{array}$ & $\begin{array}{l}\times 1.5 \\
\times 6 \\
\times 4.5\end{array}$ & $\begin{array}{lr}0- & 3 \\
0- & 12 \\
0- & 9\end{array}$ \\
\hline $\begin{array}{l}\text { (4) Hemianopia } \\
\text { (5) Aphasia (none, mild, moderate, severe, total) }\end{array}$ & & $0-2$ & $\begin{array}{l}\times 3 \\
\times 10\end{array}$ & $\begin{array}{lr}0- & 6 \\
0- & 40\end{array}$ \\
\hline (6) Higher cortical function & $\left\{\begin{array}{l}\text { Frontal } \\
\text { Parietal }\end{array}\right.$ & $\left.\begin{array}{l}0-2 \\
0-2\end{array}\right\}$ & $\times 12$ & $0-48$ \\
\hline $\begin{array}{l}\text { (7) Mental confusion } \\
\text { (8) Forced gaze } \\
\text { (9) Incoordination } \\
\text { (10) Dysarthria } \\
\text { (11) Dysphagia }\end{array}$ & & $\begin{array}{l}0-3 \\
0-2 \\
0-3 \\
0-3 \\
0-2\end{array}$ & $\begin{array}{l}\times 15 \\
\times 2 \\
\times 3 \\
\times 2 \\
\times 4\end{array}$ & $\begin{array}{lr}0- & 45 \\
0- & 4 \\
0- & 9 \\
0- & 6 \\
0- & 8\end{array}$ \\
\hline
\end{tabular}

\section{STATISTICAL METHODS}

Sample size-A previous study using a similar scoring system provided data for calculation of sample size. ${ }^{5}$ The mean percentage change in weighted stroke scores from day 1 to day 21 was estimated for the placebo group (the usual course of the condition) and used to decide whether a $25 \%$ or a $50 \%$ therapeutic effect was more appropriate: (score day $1-$ score day $21) /$ score day $1(\times 100)=\%$ change in score. The mean percentage decrease in stroke score over 21 days in the placebo group was 28.6 (SEM 24.7) for 17 patients. A $25 \%$ improvement with treatment would have a scarcely detectable clinical effect, requiring 205 patients in each group (using the formula $n=2[((z \alpha-z \beta) \sigma) / \delta]^{2}$, and assuming $\left.\alpha=0.05, \beta=0.10\right)$, whereas a $50 \%$ improvement would confer significant clinical benefit and require 52 patients in each group.

Statistical analysis - The effect of independent factors in the two groups, including active drug treatment, was evaluated by logistic regression. ${ }^{11} \mathrm{~A}$ log 
rank test and Cox regression compared the relative hazard rate of the two groups, accounting for the censoring of observations due to death or withdrawal. ${ }^{12}{ }^{13}$ Kaplan-Meier survival curves were generated to compare the two groups, both with survivors only and with survivors plus withdrawals and deaths. ${ }^{1+}$ Scores in the two survivor groups were compared using analysis of variance with data from patients with a complete set of assessments. Student's $t$ tests evaluated the differences in the mean baseline scores, the mean final scores, and change in the mean scores in each group. Spearman correlations were performed between study groups treated as a binary variable, using the neurological scores at each observation. ${ }^{15}$

\section{Results}

Of 270 consecutive patients admitted to the stroke unit, $11 ?$ met the entry criteria and were allocated at random to receive steroid or placebo (table II). The groups were identical except that the placebo group had significantly more cardiac disease (table III). Seven of the 54 patients in the steroid group and six of the 59 given placebo were withdrawn because of presumed side effects (table IV).

There was no significant difference in the death rate or in neurological outcome between the two groups, whether the survivors were evaluated separately (fig) or the scores of patients who died were included (table V). More patients died of coning in the placebo group than in the steroid group, but this difference also was not significant (table VI).

\section{Discussion}

Previous attempts at controlled or double blind trials of steroids in stroke ${ }^{1.51617}$ were performed in an era when sample sizes were inadequate or when cerebral infarction could not easily be differentiated from haemorrhage. An expert group outlined the basic principles of future stroke drug trials in $1977,{ }^{18}$ yet their advice remained largely unheeded.

Stroke is an imprecise term encompassing various pathological states, mostly cerebral infarction and haemorrhage. Clinical diagnosis of stroke is inaccurate,,$^{19}$ and studies are invalid without computed tomography (or at least radionuclide imaging) to confirm the lesion. The pathology of cerebral infarction and haemorrhage differs, and there is no rationale for a similar response to steroid treatment of the mass effect of haematoma and the vasogenic oedema of ischaemia. ${ }^{20}$

The validity of drug trials in stroke depends on the qualitative and quantitative validity of the neurological assessment. The Toronto stroke scoring system correlates significantly with clinical function. ${ }^{9}$ Scoring methods are as numerous as their authors ${ }^{3.5}$ : some emphasise unusual sequelae of stroke such as "confusion" or urinary incontinence, or evaluate functionless variables such as pupil size or

TABLE II-Treatment and outcome in the 113 patients included in trial

\begin{tabular}{lccccc}
\hline & & & \multicolumn{2}{c}{ Outcome in those remaining in trial } \\
\cline { 5 - 7 } & $\begin{array}{c}\text { No } \\
\text { randomised }\end{array}$ & $\begin{array}{c}\text { No } \\
\text { withdrawn }\end{array}$ & $\begin{array}{c}\text { Total } \\
\text { remaining }\end{array}$ & $\begin{array}{c}\text { No (\%) } \\
\text { Died }\end{array}$ & $\begin{array}{c}\text { No (\%) } \\
\text { Survived }\end{array}$ \\
\hline Steroid group & 54 & 7 & 47 & $13(27 \cdot 7)$ & $34(72 \cdot 3)$ \\
Placebo group & 59 & 6 & 53 & $15(28 \cdot 3)$ & $38(71 \cdot 7)$ \\
\hline Total & 113 & 13 & 100 & 28 & 72 \\
\hline
\end{tabular}

TABLE III-Matching of relevant variables at entry to study

\begin{tabular}{lccc}
\hline & $\begin{array}{c}\text { Steroid group } \\
(\mathrm{n}=54)\end{array}$ & $\begin{array}{c}\text { Placebo group } \\
(\mathrm{n}=59)\end{array}$ & p Value \\
\hline Age (years) & 73 & 76 & $\mathrm{NS}$ \\
Sex $(\mathrm{M}: \mathrm{F})$ & $24: 30$ & $28: 31$ & $\mathrm{NS}$ \\
Delay in treatment (hours) & 18 & 16 & $\mathrm{NS}$ \\
History: & 21 & 27 & $\mathrm{NS}$ \\
$\quad$ Hypertension & 24 & 39 & 0.02 \\
$\quad$ Cardiac & $92(4)$ & $95(4)$ & NS \\
Mean initial stroke score (SEM) & 53 & 56 & NS \\
Site: & Hemispheric & 3 & \\
$\quad$ Brain stem & 1 & & \\
\hline
\end{tabular}

TABLE IV-Complications necessitating withdrawal from study

\begin{tabular}{lcccc}
\hline & Diabetes & Infection & $\begin{array}{c}\text { Gastrointestinal } \\
\text { bleed }\end{array}$ & Total \\
\hline Steroid group & 4 & 0 & 3 & 7 \\
Placebo group & 0 & 4 & 2 & 6 \\
\hline
\end{tabular}

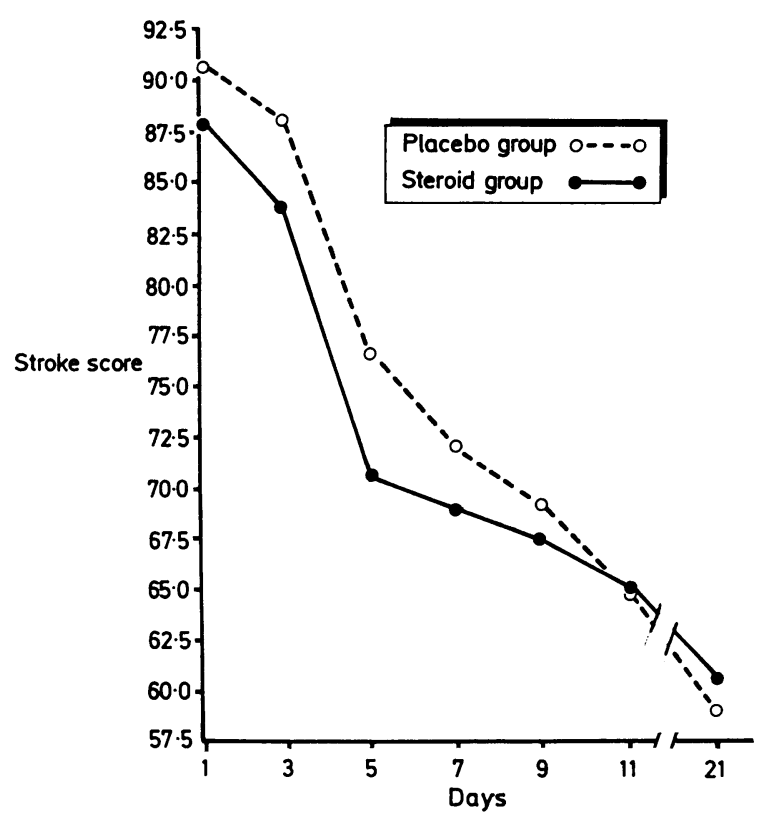

Change in stroke scores for survivors during study.

TABLE V-Comparison of mean stroke scores over course of study (survivors and fatal cases). (SD in parentheses)

\begin{tabular}{lcccc}
\hline & Initial & Day 6 & Day 12 & Day 21 \\
\hline Steroid group & $92(31)$ & $83(36)$ & $67(29)$ & $60(30)$ \\
Placebo group & $95(33)$ & $81(32)$ & $65(27)$ & $59(29)$ \\
\hline
\end{tabular}

TABLE VI-Causes of death in steroid and placebo treated groups

\begin{tabular}{lccccccc}
\hline & Coning & $\begin{array}{c}\text { Second } \\
\text { stroke }\end{array}$ & Cardiac & $\begin{array}{c}\text { Sudden } \\
\text { death }\end{array}$ & $\begin{array}{c}\text { Pulmonary } \\
\text { embolism }\end{array}$ & Infection & Total \\
\hline Steroid group & 7 & 1 & 2 & 2 & 0 & 1 & 13 \\
Placebo group & 12 & 0 & 2 & 0 & 1 & 0 & 15 \\
\hline
\end{tabular}

deep tendon reflexes. Some workers emphasise the importance of long term mortality and morbidity at periods of at least one year. ${ }^{17}$ The hypothetical effect of steroids is on acute cerebral oedema, which occurs within 10-12 days of cerebral infarction..$^{21}$ Outcome at one year has little to do with the initial neurological deficit, since later deaths are mainly cardiac, and quality of life depends on many variables such as spasticity and efficacy of rehabilitation. The longer the delay between evaluation and the time of initial treatment the more difficult it is to attribute any change to that treatment.

Sample size is critical and depends on the acceptable difference in outcome and on the random error inherent in the measurements. Statistical conclusions and acceptable $p$ values are invalid if sample size is insufficient. ${ }^{22}$ There was no significant difference in the number of patients coning in the steroid and placebo groups, but the relatively small sample used in this study may have missed a therapeutic effect (beta error). Larger numbers of patients, available in a multicentre study, might show a significant effect. Coning in cerebral infarction occurs only with extensive brain damage from the mass effect of cerebral oedema ${ }^{2123}$ and steroids would therefore prevent death only in patients with massive infarcts, rendering them semivegetative survivors. 
In the large study required to detect a significant effect of steroids on coning many patients would be exposed to the hazards of steroids, including infection, hypoglycaemia, and gastrointestinal haemorrhage. The dubious advantage of preventing death in seriously afflicted patients would be offset by exposing a wide range of patients believed to have "stroke" to the side effects of the drug. Such indiscriminate use of steroids might also result in serious side effects in survivors who would otherwise recover uneventfully. Dyken and White abandoned an early trial of steroids in stroke because patients given the active drug fared worse than those given placebo. ${ }^{16}$ In a later negative study steroid induced diabetes caused serious reactive hypoglycaemia and systemic infections left permanent sequelae in some patients. ${ }^{5}$ Larger multicentre studies to identify a subgroup of patients who might benefit from steroids are therefore unjustified.

We thank Bette Shurvell and Cecily Ziliotto for their help in compiling and analysing the data, Terry Germanson for help with the statistical analysis, and Barbara Huth for her help in editing the manuscript. Dr J G Edmeads kindly allowed us to include some of his patients in the study. A grant from the Heart and Stroke Foundation of Ontario enabled us to perform the study, and VCH was supported as a research associate of the foundation.

\section{References}

1 Rubinstein MK. The influence of adrenocortical steroids on severe cerebrovascular accidents. $\mathcal{f}$ Nerv Ment Dis 1965;141:291-9.
2 Russek HI, Russek AS, Zohman BL. Cortisone in immediate therapy of apoplectic stroke. $\mathcal{F A M A}$ 1955;159:102-5.

3 Patten BM, Mendell J, Bruun B, Curtin W, Carter S. Double-blind study of the effects of dexamethasone on acute stroke. Neurology (NY) 1972;22:377-83.

4 Bauer RB, Tellez H. Dexamethasone as treatment in cerebrovascular disease. 2. A controlled study in acute cerebral infarction. Stroke 1973;4:547-55.

5 Norris JW. Steroid therapy in acute cerebral infarction. Arch Neurol 1976;33:69-71, 374-5.

6 Patten BM. Steroid therapy in acute cerebral infarction. Arch Neurol 1976;33:374.

7 Braakman R, Schouten HJA, Blaauw-van Dishoeck M, Minderhoud JM. Megadose steroids in severe head injury. Results of a prospective double-blind clinical trial. $\mathcal{F}$ Neurosurg 1983;58: $326-30$.

8 Faupel G, Reulen HJ, Mueller D, et al. Double-blind study on the effects of steroids on severe closed head injury. In: Pappius HM, Feindel W, eds. Dynamics of brain edema. Berlin: SpringerVerlag, 1976:337-43.

9 Norris JW, Hachinski VC. Comment on "study design of stroke treatments." Stroke 1982;13: $527-8$.

10 Spiro HM. Is the steroid ulcer a myth? N Engl f Med 1983;309:46.

11 Cox DR. The analysis of binary data. New York: Halsted Press, 1970.

12 Cox DR. Regression models and life tables. Foumal of the Royal Statistical Society 1972;34: 187-220.

13 Peto R, Pike MC, Armitage P, et al. Design and analysis of randomized clinical trials requiring prolonged observation of each patient. II. Analysis and examples. Brf Cancer 1977;35:1-39.

14 Kaplan EL, Meier P. Nonparametric estimation from incomplete observations. Fournal of the American Statistical Society 1958;53:457-81

15 Diem K, Lentner C, eds. Scientific tables. 7th ed. Basle: Ciba-Geigy, 1970:181

16 Dyken $M$, White PT. Evaluation of cortisone in the treatment of cerebral infarction. FAMA 1956;162:1531-4.

17 Mulley G, Wilcox RG, Mitchell JRA. Dexamethasone in acute stroke. Br Med f 1978;ii:994-6. 18 Katzman R, Clasen R, Klatzo I, Meyer JS, Pappius HM, Waltz AG. Report of Joint Committee for Stroke Resources. IV. Brain edema in stroke. Stroke 1977;8:512-40.

19 Norris JW, Hachinski VC. Misdiagnosis of stroke. Lancet 1982;i:328-31.

20 Fishman RA. Steroids in the treatment of brain edema. N Engl f Med 1982;306:359-60.

21 Shaw CM, Alvord ED Jr, Berry RG. Swelling of the brain following ischemic infarction with arterial occlusion. Arch Neurol 1959;1:161-77.

22 Taylor DW, Sackett DL, Haynes RB. Sample size for randomized trials in stroke prevention. How many patients do we need? Stroke 1984;15:968-71.

23 Brown M, Glassenberg M. Mortality factors in patients with acute stroke. JAMA 1973;224: 1493-5.

(Accepted 23 October 1985)

\section{SHORT REPORTS}

\section{Evidence of inherited urea cycle defect in a case of fatal valproate toxicity}

Liver failure deaths have occurred, mainly in children, during treatment with valproate.' The small number of cases with serious complications indicates that an inherited metabolic defect might be implicated. ${ }^{1}$ At therapeutic levels of valproate net production of ammonia in the kidney is increased $^{2}$ and urea synthesis inhibited in healthy subjects (Hjelm $e t a l$, in preparation). Thus children with hereditary urea cycle defects might be further compromised by valproate with accelerated damage of brain tissue. performed. A common feature was persistent vomiting and convulsions. The 3 year old girl was treated with valproate for six weeks and with paracetamol and metaclopramide for over one week before she died. ${ }^{1}$

Alanine was administered intravenously $(0.25 \mathrm{~g} / \mathrm{kg}$ body weight) over 10 20 minutes. Blood was drawn at intervals before and after the load for estimating ammonia (ion selective electrode) and urea. Urine was collected every 40 minutes for estimating orotate. ${ }^{4}$ The maximum increase in the rate of urea synthesis from preload values $(\hat{\mathbf{f}})$ and the time at which it occurred $(\hat{\mathbf{t}})$ were calculated from the increase in plasma urea concentration. ${ }^{3}$ This approach allows the production of orotate to be related to the turnover of metabolites in the urea cycle.

All three subjects responded to the alanine load with the same $\hat{f}$ and $\hat{t}$ as healthy subjects. The mother's response was maintained at increased plasma concentrations of ammonia and urinary excretion of orotate. This suggested accumulation

Results of investigations in family

\begin{tabular}{lcccc}
\hline & $\begin{array}{c}\mathrm{f} \\
(\mathrm{min})\end{array}$ & $\begin{array}{c}\hat{\mathrm{f}} \\
(\mu \mathrm{mol} / \mathrm{min} / \mathrm{l} \text { body water })\end{array}$ & $\begin{array}{c}\text { Urinary orotate, cumulative excretion } \\
(\mu \mathrm{mol})^{\star}\end{array}$ & $\begin{array}{c}\text { Plasma ammonia, highest value } \\
(\mu \mathrm{mol} / 1)\end{array}$ \\
\hline $\begin{array}{l}\text { Mother } \\
\text { Father }\end{array}$ & 33 & 15 & 135 & 166 \\
Son & 18 & 13 & 6 & 56 \\
\hline $\begin{array}{l}\text { Reference interval } \\
(\text { mean (2 SD) } \mathrm{n}=11)\end{array}$ & $42(23)$ & $16(8 \cdot 4)$ & 8 & 72 \\
\hline
\end{tabular}

$\hat{\mathrm{t}}=$ time at which maximum rate of synthesis occurs; $\hat{\mathrm{f}}=$ maximum rate of urea synthesis.

*Cumulative excretion during 240 minutes above the preload level during 120 minutes.

We describe here a family in which two daughters and a son died in childhood, all with clinical features suggesting a metabolic disorder and in one of whom valproate seems to have accelerated death. ${ }^{1}$ We tried to establish whether the parents and the surviving son might be heterozygotes for a urea cycle defect by carrying out standardised alanine loads.

\section{Patients, methods, and results}

The parents (aged 51 and 47 years) and the surviving son (aged 21 years), all clinically healthy, were investigated. The children who died (aged 3 (girl), 5 (boy), and 6 (girl) years) had been treated for neurological lesions ${ }^{1}$ without signs of impaired liver function. No investigations for metabolic disorders were of carbamoylphosphate in the liver, a diagnostic feature of ornithine carbamoyltransferase deficiency and provided indirect evidence that the mother was heterozygous for this deficiency (Hjelm et al, in preparation).

\section{Comment}

Ornithine carbamoyltransferase deficiency is an X linked disorder, the most common of the urea cycle defects, with variable expression in female carriers due to random inactivation of the $\mathrm{X}$ chromosome (Lyon hypothesis). Thus women vary from clinically normal to severely affected. In men the condition is often fatal in early childhood.

The dead children were probably affected by this disease and valproate 